\title{
DESIGN OF A NEW TYPE OF AUTOMATIC DRAIN COVER
}

\author{
Yakang Zhao ${ }^{1}$, Dexian $\mathrm{Ma}^{2}$, Shixiong Fü, Maohua Xiao ${ }^{4 *}$, Chengcheng Yan ${ }^{5}$, Shanshan Guo 6 \\ ${ }^{1-6}$ College of Engineering, Nanjing Agricultural University, NanJing210031,China
}

\begin{abstract}
Based on the urban drain cover, a new type of drain cover with anti - clogging, automatic row and simple structure is designed. This paper analyzes the existing problems in the drainage of the existing drain cover under different precipitation conditions, and compares the structural parameters and performance parameters of the existing drain cover and the new automatic drain cover. At the same time, the working process of the new manhole covers is analyzed, including water storage, drainage and resetting. And the structural design of the covers is calculated, and the change of the angle of the upper and lower opening of the covers with time is obtained under the fixed flow rate. The strength analysis of the upper layer of the covers is also carried out by D400 inspection. Through the PRO / E three-dimensional modeling and physical model production, and test the model to prove that the new automatic drainage rain cover is more suitable for different rainfall conditions under the drainage work, according to different rainfall automatically adjust the displacement, improve drainage performance, effective Blocking debris into the rainwater wells, reducing manpower costs.
\end{abstract}

Keywords: Drain covers; Automatic rowing; Design; Contrast

\section{Introduction}

Drain cover is one of the important components of urban drainage system, and plays a key role in the development of a city. Because the design of the existing rain well covers is not reasonable, the utility model is easy to fall into the sundries and block up when the city does not produce rainfall when the city rainfall is heavy, the existing rain well covers are not reasonable enough to eliminate the road area water in time, which leads to road pedestrian or driving difficulties and even hidden dangers. Thus, when heavy rainfall or continuous precipitation exceeds the urban drainage capacity, it will lead to the city of water disaster phenomenon "urban water logging"[1].

For serious sections of the water, the municipal departments will increase the manpower to open the manhole spillage, time-consuming and laborious, even because the covers are opened to the accident or personal injury, resulting in huge economic losses. This will not only increase the workload of municipal departments, and even lead to water logging disasters in cities because of the excessive number of heavy water sections, which will seriously threaten urban public security and cause huge economic losses.

The innovative design of domestic drain covers is not further comprehensive. Yang Zitong [2] designed an intelligent silt reduction and drainage filter cover, which can filter debris in the water and improve drainage efficiency. Xi Bin and Zhou Jiren[3] designed a lever balanced automatic rainwater drain well cover. But the processing technology of these drain covers is very complex, and the manufacturing cost is very high, and it cannot be popularized in a large scale. In view of the existing rain cover is easy to be blocked and cannot improve drainage situation in time. Therefore, it is necessary to design a kind of anti-blocking, and automatic row covers in order to solve the existing drainage problems.

\section{Structure Design of the New Automatic Drain Cover}

\subsection{Problem analysis}

At present, there are two kinds of common drain covers, one is the ordinary drain cover as shown in Fig.1, and this kind of manhole covers is not much different from the sewage inspection covers and electric power inspection covers. When rainfall is heavy, this drain cover cannot meet the need of drainage, what's worse, it even need to manually open for drainage, time-consuming and arduous.

Another kind of drain cover is the rain well grate as shown in Fig. 2.Although this way of drainage is better than ordinary rain covers, it is much likely to be blocked by debris, hence, its reliability is not high. 


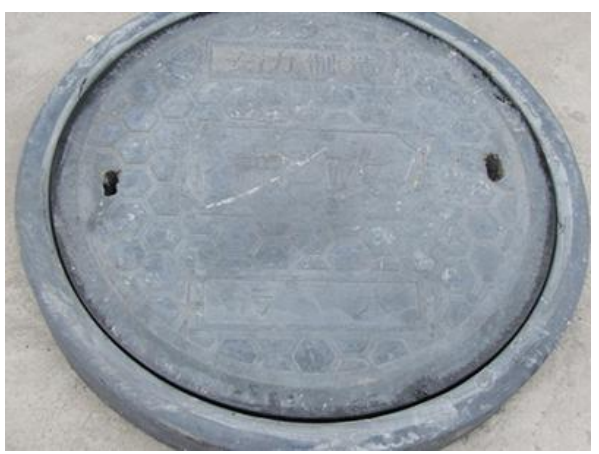

Figure 1. Ordinary rain cover on the road

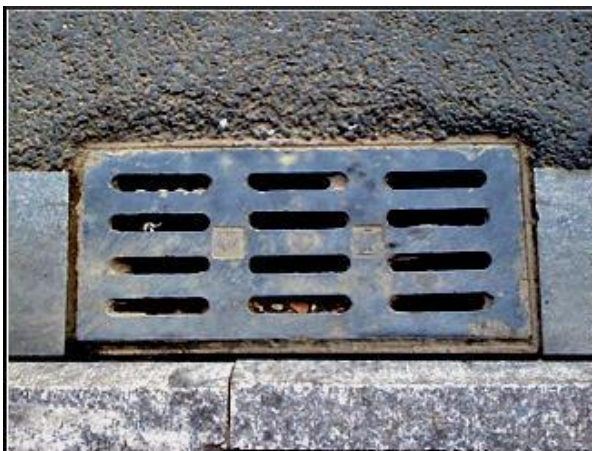

Figure 2. Rainwater baron both sides of the road

\subsection{Design requirements}

Considering the actual working environment and work requirements of the new type of automatic drain cover, the device needs to meet the following design requirements:

(1)Can be based on the different rainfall automatically adjust the size of the displacement;

(2)Can prevent from blocking when it is not raining;

(3)The structural strength can satisfy the traffic demand of main roads and highways in the city.

\subsection{Two-layer structure design of covers}

The model covers combines the structure advantages of the existing manhole cover and rain well grate, which was composed of two layers and a water storage vice (looks like a keg). The upper cover was provided with a drain hole groove, as shown in fig.4, and the lower cover plate is matched with the upper well cover. The upper layer and the lower layer are connected together through a pin shaft. There's a water storage vice below the lower layer, in which was rainwater flowing through the whole lying in the upper layer. The weight of water in the water storage determines the angle between the upper layer and the lower layer, which depends on the amount of rainfall. The structure of a drain cover can not only solve the blocking problem, but also avoid manual assistance for drainage, meanwhile it can drain water with an appropriate flow automatically due to the amount of rainfall.

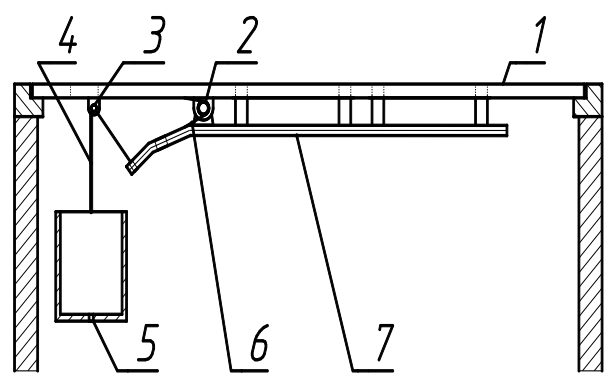

1. Upper cover ; 2. Pin shaft ; 3 . Fixed pin ;

4. Hanging line ; 5 . Water storage device ;

6. Return torsion spring ; 7. Lower cover

Figure 3. Structure of the automatic drain cover

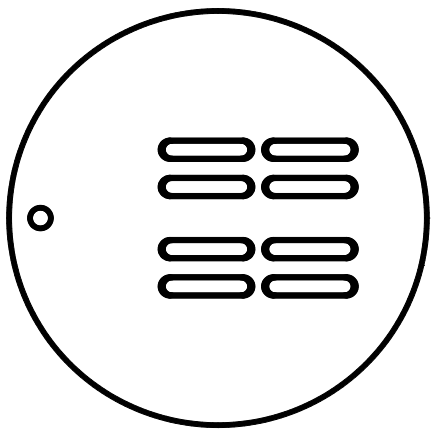

Figure 4. Structure of the upper cover

The upper well covers have a drain hole and eight through-hole slots. A deal of rainwater can flow from the drain hole into the water storage device to control the angle between the upper cover and the lower one, which determines the water-carrying capacity of the automatic drain cover. And most of rainwater drain through the eight through-hole slots. The upper and lower layers are hinged by a pin shaft which is through a torsion spring. When it doesn't rain, the lower cover is tightly pressed down under the upper cover because of the force from the torsion spring. The water storage device (looks like a keg) is placed below the drain hole, on the bottom of which there is a small thorough-hole. The water storage device is connected to the fixed pin on the lower cover by means of a hanging thread. The upper covers are made of ductile cast iron. According to GB/T 23858-2009[4], its thickness is $65 \mathrm{~mm}$ and its diameter is $700 \mathrm{~mm}$. The cross-sectional area of eight through-hole slots is $0.0371 \mathrm{~m}^{2}$, accounting for $9.64 \%$ of the upper cover area. The lower cover plate and the water storage device are made of resin composite material to reduce the overall quality.

\subsection{Working principle}

As shown in Fig. 3, the new automatic drain cover composes of the upper cover, pin shaft, fixed pin, suspension thread, water storage device, reset torsion spring and the lower cover. When it is not raining, the lower cover is tightly pressed down under the upper cover because of the force from the torsion spring, which can prevent the through-hole 
slots from blocking by rubbish. When there is water on the upper well cover, the water flows into the water storage device through the small drain hole of the upper well cover. With the increase of water storage device's gravity, the pull of an end of the suspension thread is augm enting. Therefore, the pull on the other end of the suspension thread can overcome the clamping force of the torsion spring so that the lower cover rotates around the pin shaft, hence, there angle between the lower cover and the upper cover is increasing slowly. Meanwhile, the water can flow through the through-hole slots.

When the drainage decreases, the water in the water storage device flows out from the water storage device, hence, the pull of the suspension thread is reducing, at the same time, the angle between the upper cover and lower cover is decreasing. Finally, the lower cover would be tightly pressed down under the upper cover again when flow decreases to zero. The whole working processes is shown in Fig. 5.The advantage of using water's gravity to open a channel is energy-saving and environmentally friendly.

The 3D-printing model of the automatic drain cover was drawn by CREO2.0, and its working environment is simulated as shown in Fig. 6.

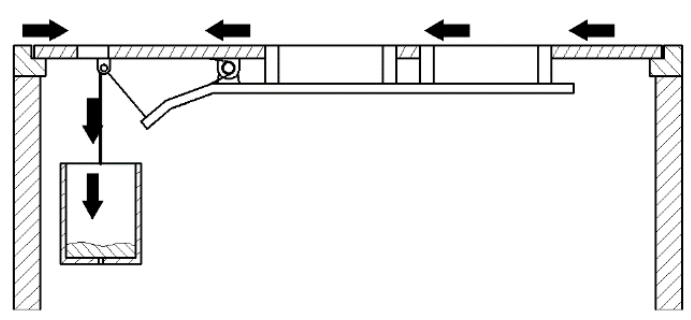

(a) Water storage process

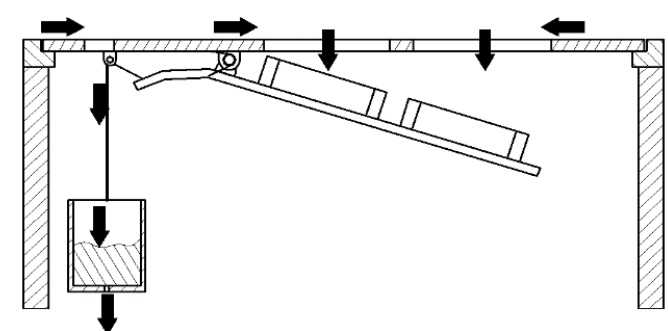

(b) Drainage process

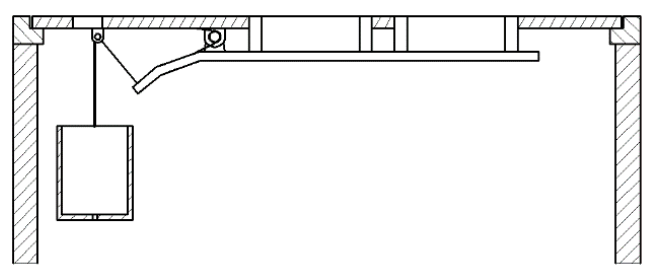

(c)Reset state

Figure 5. The working process of new drain cover

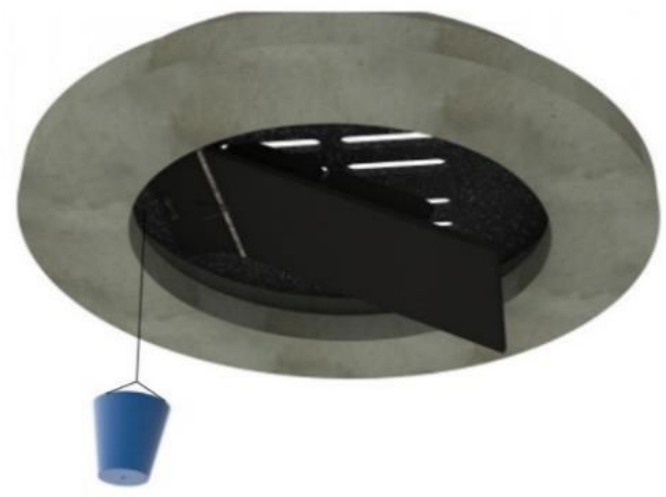

Figure 6. The working condition of the drain cover

\section{Analysis and Calculation of the 3D- Printing Model of the Automatic Drain Cover}

\subsection{Mathematical model in the work of manhole cover}

Suppose that the flow of the drain hole on the upper cover is a certain positive value of number$\mathrm{Qkg} / \mathrm{s}$, the cross-sectional area of the water storage device is $\mathrm{A} \mathrm{mm^{2 }}$ and use $\mathrm{s}(\mathrm{h})$ to stand for the relationship between the drain hole's cross-sectional area and the water height of the water storage device. At any given time $t$, the water's height $h(t)$ in water storage device can be described as the following formula:

$$
\begin{aligned}
& \int_{0}^{h(t)} s(h) d h(t)=\frac{Q}{10^{3}} \bullet t-\int_{0}^{t} q(t) d t \\
& q(t)=\mu \bullet A \bullet \sqrt{2 g h(t)}
\end{aligned}
$$

In formula: $q(t)$ - - the flow of water through the drain hole

to 0.62 ;

$\mu$-—outflow flow coefficient, take 0.60

The water storage device is a regular drum with constant cross-sectional area,then $\mathrm{s}(\mathrm{h})$ is a constantS.

Formula (1) the derivative of time $t$ on both sides can be obtained:

$$
S \bullet h^{\prime}(t)=\frac{Q}{10^{3}}-\mu \bullet A \bullet \sqrt{2 g h(t)}
$$

Because the gravity of the lower cover and the water storage device is small, it can be ignored.

Therefore, we can calculate the torque of the pin shaft. When the torque produced by suspension can not offset the tightening torque produced by the reset torsion spring, the upper and lower cover cannot open an angle. Thus, the separation angle's formula of the upper and the lower cover can be obtained. 


$$
\begin{aligned}
& \varphi=\left\{\begin{array}{l}
0 \cdots \cdots \cdots \cdots \cdots \cdots \cdot P \bullet L<M \\
\frac{P \bullet L-M}{C} \cdots \cdots \cdots \cdot P \bullet L \geq M
\end{array}\right. \\
& P=S \bullet h(t) \bullet 10^{3}
\end{aligned}
$$

In formula: $P$ - the gravity of the water storage device at the time of $\mathrm{t}$;

$L$ - - the distance from the point of the suspension thread and the lower cover to the pin shaft;

C-_-stiffness coefficient of the reset torsion spring;

$M-$ - pretension torque of the reset torsion spring; spring.

$\varphi$ - the angle of rotation of the reset torsion

To measure the model, some parameters can be obtained, listed in Tab. 1:

Table 1 Partial structural parameters of the covers

\begin{tabular}{|l|l|}
\hline \multicolumn{1}{|c|}{ Structure } & \multicolumn{1}{c|}{ Size } \\
\hline \multirow{3}{*}{ Water Storage Device } & Cross-sectional diameter is $0.1 \mathrm{~m}$ \\
\cline { 2 - 2 } & The diameter of the drain hole is $0.01 \mathrm{~m}$ \\
\cline { 2 - 2 } & Outflow flow coefficient 0.6 \\
\hline The distance from hanging line to pin shaft & $0.1067 \mathrm{~m}$ \\
\hline Reset torsion spring & Torsion rigidity is $3328.22 \mathrm{~g} \bullet \mathrm{mm} / \mathrm{deg}$ \\
\cline { 2 - 2 } & Preload torque is $86533.75 \mathrm{~g} \cdot \mathrm{mm}$ \\
\hline
\end{tabular}

\subsection{Analysis of the working characteristics of the cover}

When the constant flow rate $Q=0.1 \mathrm{~kg} / \mathrm{s}$, Solving equations formula (3) and formula (4) can obtain the relation between the height of the water in the water storage device and time, meanwhile, we can also obtain the relation between the opening angle of the upper and lower cover and time, as shown in fig. 7. According to the calculation results, when $Q$ equals $0.1 \mathrm{~kg} / \mathrm{s}$, it takes 60 seconds for the water storage device to store $0.2 \mathrm{~m}$ water. And it would take about 104 seconds for the water storage device to store the maximum height of water $-0.22 \mathrm{~m}$. It takes 15.7 seconds for the lower cover to reach the maximum angle--31. $8^{\circ}$

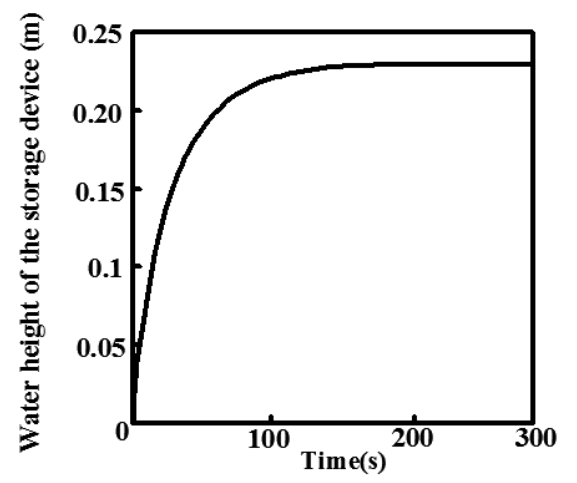

(a) The relation between water height and time of water storage device
If the flow $Q$ equals $0 \mathrm{~kg} / \mathrm{s}$ and the initial water height in the storage device is $0.22 \mathrm{~m}$, the relation between the height of water decreasing and time,and the open angle closing with time, as shown in fig. 8. In the absence of an inflow of external water, it takes 33.11 seconds for the water storage device to finish draining away water. The upper and lower takes 12 seconds to close. The storage capacity of the water storage device is related to the cross-sectional area and the area of the bottom hole. In the case of water flow and cross-sectional area known, the larger the area of the bottom hole is, the lower the maximum water in the water storage device is. This shows that when the height of the water storage device is constant, we can increase the area of the bottom hole to increase the maximum storage capacity, which can cope with more serious water logging situation.

Figure 7. The opening characteristics of the cover in a constant flow 


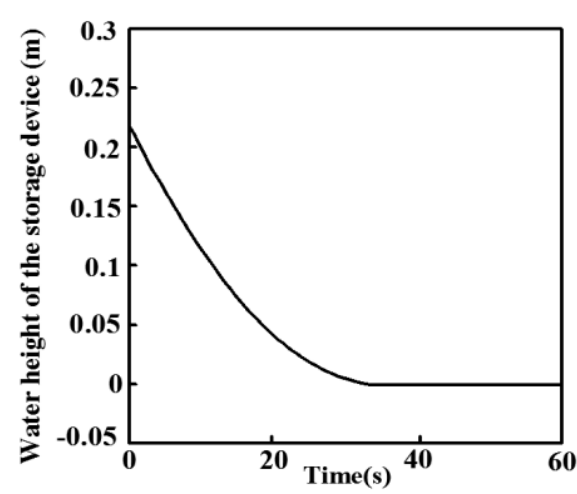

(a) The relationship between water level and time of water storage device

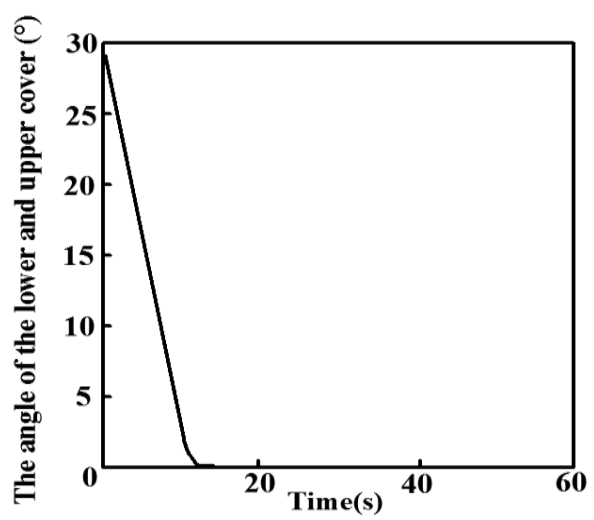

(b) The relationship between the angle of the lower cover and the time

Figure 8. The closing characteristics of the cover in a constant flow

\section{Strength Analysis Based on Ansys}

\subsection{Establishment of finite element model}

The common failure forms of mechanical parts are static strength failure, fatigue strength failure, stiffness failure and vibration failure, etc ${ }^{[6]}$. Using a CAD software to build solid model, and then import it into ANSYS for finite element analysis, which is a commonly used finite element analysis method. The upper cover is vulnerable part of the whole drain cover, which bear the weight of vehicles, pedestrians and rainwater. Deformation and rupture are the main failure forms of the upper cover, hence it's necessary to analyze the static strength of the upper cover. First, create a 3D model of the floating upper cover by CREO. Second, save it as an STP format, and import it into the ANSYS software.

In CREO, the upper cover's diameter is $700.00 \mathrm{~mm}$ and its thickness is $65.00 \mathrm{~mm}$. In ANSYS, just apply a $1.415 \mathrm{MPa}$ intensity ........./Youdao Dictionary(Locate)/Dict/7.5.0.0/res ultui/dict/?keyword=of

........./Youdao Dictionary(Locate)/Dict/7.5.0.0/res ultui/dict/?keyword=pressure on the upper, which is equivalent to the particular concentrated force ${ }^{[9]}$.Because the external load is larger than the gravity of the water storage device, so the latter can be neglected. When calculating the strength of the upper cover in ANSYS, several parameter need setting. Because the upper cover's parameter, its elasticity

........./Youdao Dictionary(Locate)/Dict/7.5.0.0/res ultui/dict/?keyword=modulus-E equals 173GPa,its ........./Youdao Dictionary(Locate)/Dict 77.5.0.0/resultui/dict/?keyword=shear

......././Youdao Dictionary(Locate)/Dict/7.5.0.0/res ultui/dict/?keyword $=$ modulus-G equals $74.5 \mathrm{GPa}$, its Poisson's ratio $\mu$ equals 0.30 , and its density- $\rho$ equals $7.3 \times 10^{3} \mathrm{~kg} / \mathrm{m}^{3}$. With the way of automatically dividing the grid, the grid size is $1 \mathrm{~mm}$, hence, the upper cover is divided into 189367 nodes and
114383 unit tetrahedrons, and the finite element grid model is shown in Fig.10.

\subsection{D400 level[10] inspection}

Referring to the basic assumptions in the literature[11], establish constraints analyse the load of the upper cover's model as shown in Fig.9.By using the ANSYS to analyze the well cover model, the result is shown in Fig.11. As is shown in Fig.11, the maximum deflection is $0.1023 \mathrm{~mm}$, and the maximum stress is $58.161 \mathrm{MPa}$, which is less than the ductile iron's yield value of stress-294MPa.

According to the analysis results, the cover meets the strength requirements and is suitable for roads including highways, and expressways in a city and other areas.

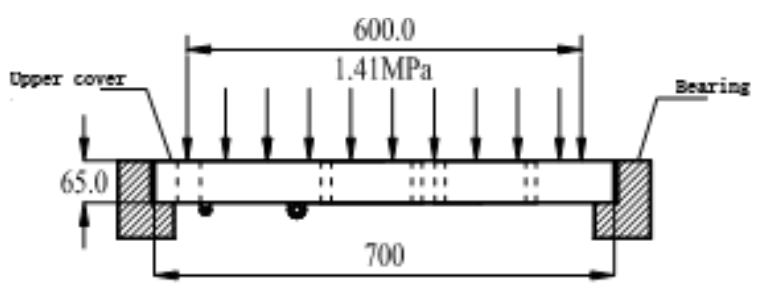

Figure 9. Model of drain cover

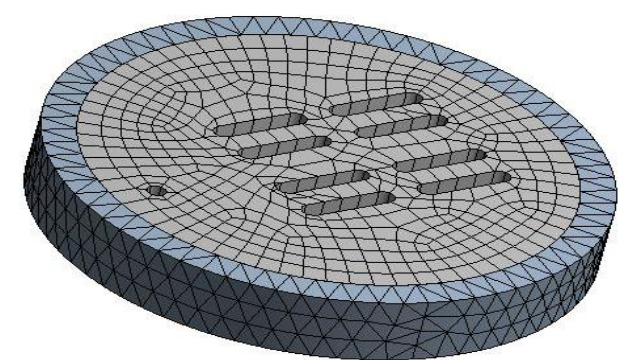

Figure 10. Finite element mesh model of the upper cover 


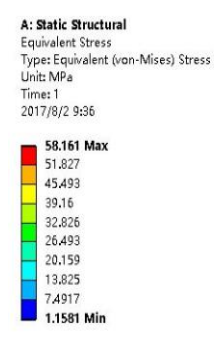

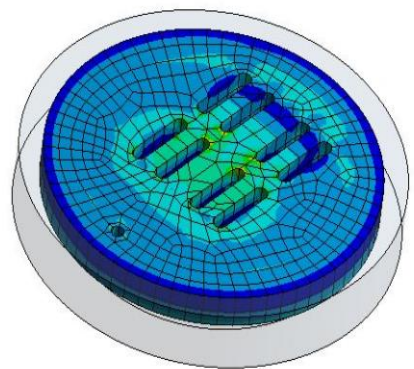

(a) Stress cloud
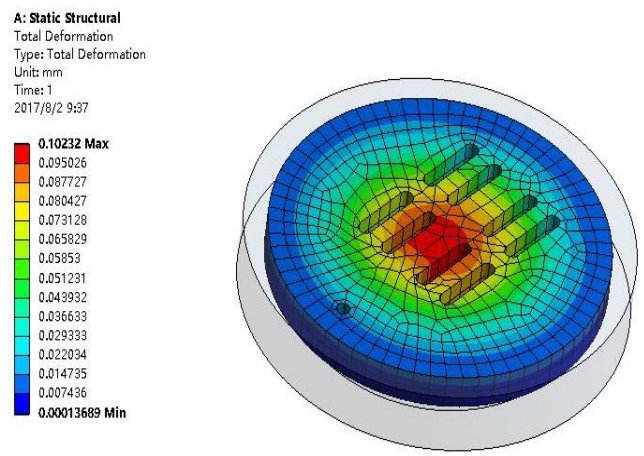

(b)Deformation cloud

Figure 11. Finite element analysis results inside the cover

\section{Physical Model Making, Testing and Comparison with Actual Covers}

\subsection{Production of physical model}

In order to verify the rationality of the drain cover's structure, we use 3D printer to print the model of the upper cover and the lower cover, concretely the diameter of the upper cover's model is $200.00 \mathrm{~mm}$ and the lower cover's size is reduced according to the proper proportion. The models is shown in Fig. 12. The material of this model is the commonly used ABS resin by the printer.

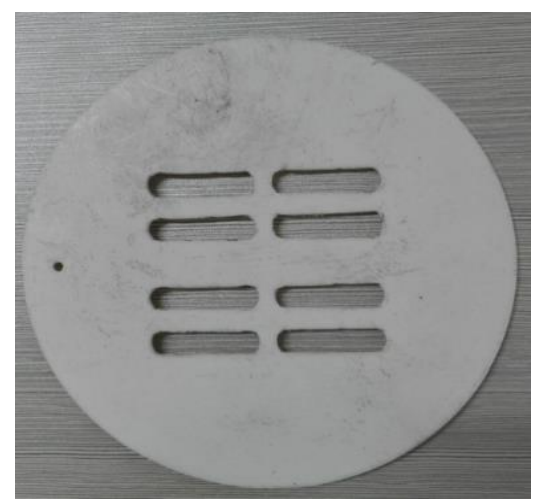

(a) The model of upper cover

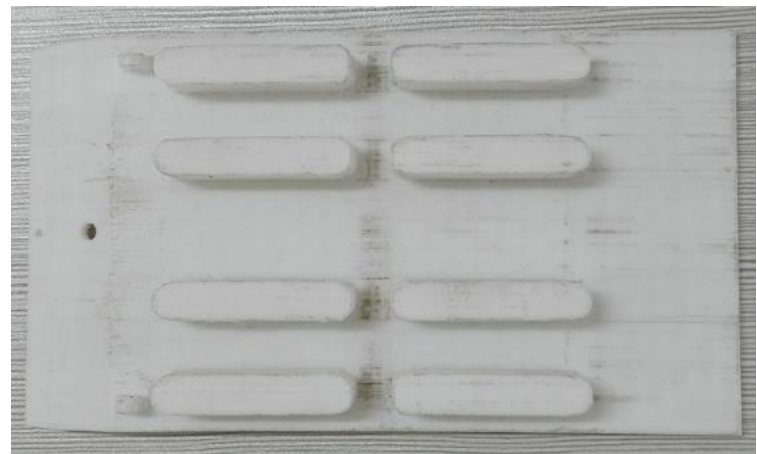

(b) The model of the lower cover Figure 12. The model of the drain cover

\subsection{Test of physical models}

To demonstrate the water storage and drainage process of the drain cover, we use the assembled models to do a multiple of experiments, in which we can clearly watch the opening and closing process of the lower cover.

By adding water to the water storage device through the drain hole, the pull of the suspension thread is augmenting slowly, so the angle between the upper cover and the lower cover is increasing gradually.

What's more, the angle between the upper cover and the lower cover is decreasing gradually while water in the water storage draining away.
This is because the pull of the suspension thread is reducing slowly. The results manifest that the new drain cover model can achieve desired courses of actions and aims and accord with the initial theoretical calculation.

In order to determine the weight of the water storage device when the lower cover begins to unscrew, be completely unscrewed and reset to completely close three states, we use a precise electronic scale to weigh the weight of the storage device. The measurements are shown in Fig. 13 and several key weights are listed in Tab.2. 


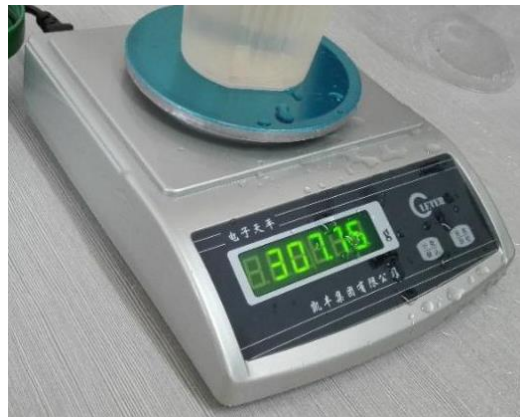

(a) Weight when the lower cover completely unscrewed

Figure 13. Water weight when the model in different states (g)

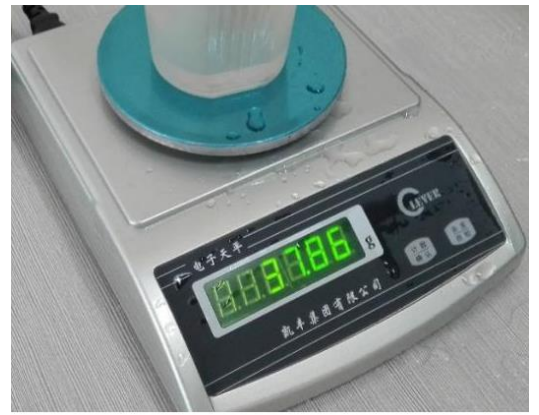

(b)Weight when cover model reset to full closure

Table 2 Water weight when the drain cover model in different states $(g)$

\begin{tabular}{|l|l|l|l|l|l|l|}
\hline & Exp.1 & Exp.2 & Exp.3 & Exp.4 & Exp.5 & Averages \\
\hline $\begin{array}{l}\text { Begin to } \\
\text { unscrew }\end{array}$ & 49.73 & 50.27 & 48.94 & 48.83 & 47.68 & 49.09 \\
\hline $\begin{array}{l}\text { Completely } \\
\text { unscrewed }\end{array}$ & 307.75 & 305.67 & 309.81 & 308.72 & 308.59 & 308.11 \\
\hline $\begin{array}{l}\text { Reset to full } \\
\text { closure }\end{array}$ & 37.86 & 36.75 & 38.52 & 39.63 & 38.37 & 38.41 \\
\hline
\end{tabular}

The experimental data of 5 groups in Tab.2 were analyzed, according to the formula of gravity calculation.

$$
G=m \bullet g
$$

In formula: $g=9.807 \mathrm{~N} / \mathrm{kg}$

From the experimental results, if flow increases gradually from zero, when the water storage device provides $0.481 \mathrm{~N}$-force, the lower cover begin to unscrew; when the water storage device provides $3.022 \mathrm{~N}$-force, the lower cover is completely unscrewed. Otherwise, while water flowing away from the storge device and the the lower cover reset to full close, the weight of the storge device is $0.377 \mathrm{~N}$.

\subsection{Comparison of physical model with actual drain cover}

The density of ABS material is $1.057 .3 \times 10^{3} \mathrm{~kg} / \mathrm{m}^{3}$ while the density of ductile iron is $7.3 \times 10^{3} \mathrm{~kg} / \mathrm{m}^{3[12]}$. Covers model is actual cover according to the proportion of 1:35 to shrink, in fact, actual covers' diameter is $700 \mathrm{~mm}$ while model's diameter is $20 \mathrm{~mm}$.

Several tests on the model acquire the precise values of weight of the water storage when the model begins to unscrew, be completely unscrewed and reset to full closure.

The covers 's model are produced by 3D printing technology and the course of working is efficient. And the model can simulate the actual processes well.

\section{Conclusion}

A new type of drain cover's structure is designed in this paper, and the drainage capacity is increased compared to the original drain cover.

At the same time, the new drain cover can change the flow of drainage in different rain flow automatically. What's more, its structure is easy to manufacture and it doesn't need electricity. Moreover, it doesn't take much money to produce. When the rainfall is heavy, it doesn't manpower to operate, so the economic loss and personal injury caused by water flow can be reduced.

By the analysis of its working characteristics, the D400 level inspection proves that the structure of the drain cover has good stability, and it is suitable for the main roads in some areas where the rainwater is hard to drain away. The analysis method used in this paper is cheap, and reduce time to produce an actual drain cover to do experiments. Therefore, the way has important reference significance in practical application. At the same time, it provides new methods and ideas for the design of other covers in the field of urban construction. 


\section{References}

[1] Hui Cen Yi, Zhou Ding. Reflections on the construction of ecological environment by urban water logging [J]. Chinese dwelling, 2011(10): 1920

[2] Yang Zi Tong. Study on the application of intelligent silt reducing and accumulating filter [J]. Scientific Chinese, 2016 (7X) 75

[3] Xi Bin, Zhou Ji Ren. Leveraged balance of drain cover [P]. Chinese patent: 201420136570, 2014-08-20(In Chinese).

[4] National standards of People's Republic of China. GB/T 23858-2009

[5] Han Guo Jun. Foundation and Application of Fluid Mechanics [M]. Machinery Industry Press, 2015:107-108

[6] YU Tian Xiang, SONG Bi Feng, WAN Fang Yi, FENG Yun Wen. Research on calculating the reliability of mechanical component with correlated failure modes [J]. Journal of Mechanical Strength, 2006, 28(4): 508-511

[7] OUYANG Zhen Guo, MA Zong Xiong, YOU Yi Min, LI Jia, XIAO Liang Xian. Design and analysis of connecting rod of disconnector based on ANSYS Workbench [J]. Journal of Mechanical Strength, 2015(5): 988-991

[8] Liang Y, Cui C Y. Simulation and Analysis for Composite Casing Aging Trend Based on ANSYS [J]. Applied Mechanics \& Materials, 2014, 668669:248-252.
[9] Hu Xian Kun, Qian Cheng. Force Analysis of new compound manhole cover based on ABAQUS [J]. Low Temperature Architecture Technology | Low Temp Archit Technol, 2014, 36(11) :58-60

[10]Peng Le i. Comparison of national standards for covers [J]. Shanghai Gas, 2006(6) :38-39.

[11] Wang Hong Lin, Li Hong Zhuo, Li De Zhang, LI Dian Zhong. Finite Element Analysis of Municipal Road Inspection Well and Surrounding Pavement [J]. Engineering and Construction. 2010, 24(1): 46

[12] Lin Zhao Qin, Chen Ji Ming. Study on the microstructure and graphite carbon behavior of ductile iron during heat treatment [J]. Science \& Technology of Baotou Steel (Group) Corporatio, 1988(4):33-34

\section{About the Corresponding author: \\ Maohua Xiao, associate professor, research direction for modern mechanical design theory and methods. Address: Nanjing University of Science and Technology, Nanjing, Jiangsu Province, China E-mail: xiaomaohua@njau.edu.cn}

\section{Fund Project:}

Central University basic scientific research business expenses special funds (KYZ201760)

SRT program supported by Nanjing Agricultural University (1530A23) 